\title{
EFEK GOAL COMMITMENT, LINGKUNGAN LITIGASI DAN KEPERCAYAAN PADA PENERIMAAN AUDITOR ATAS METODE PILIHAN KLIEN (STUDI EMPIRIS PADA KAP JAKARTA)
}

\author{
Rudi Zulfikar \\ Fakultas Ekonomi Universitas Sultan Ageng Tirtayasa \\ Rita Rosiana \\ Fakultas Ekonomi Universitas Sultan Ageng Tirtayasa \\ Kristin Romauli \\ Alumni Fakultas Ekonomi Universitas Sultan Ageng Tirtayasa
}

\begin{abstract}
The purpose of this research is to examine three factors that affect audit decision such as goal commitment, litigation environment and trust on auditor's acceptance of the client's preferred methods. Data were collected through questionaires using purposive sampling method. Samples were selected from accounting firms which were listed on Directory of Ikatan Akuntan Publik Indonesia for 2013 period in Jakarta. Out of the 150 questionnaires sent, the final analysis was based on the response from 109 auditors (72.67\%). Moreover, data analysis uses Structural Equation Model (SEM) by using AMOS (Analysis of Moment Structures) version 21.0. The results of this research reveal that (1) goal commitment is positively related to the auditor's acceptance of the client's preferred method, (2) litigation environment is negatively related to the auditor's acceptance of the client's preferred method, and (3) trust is negatively related to the auditor's acceptance of the client's preferred method
\end{abstract}

Key words: Goal commitment, litigation environment, trust, aggressive financial reporting, and client's preferred method

\section{Pendahuluan}

Laporan auditor merupakan sarana bagi auditor untuk menyatakan pendapatnya, atau apabila keadaan mengharuskan, untuk menyatakan tidak memberikan pendapat.Laporan keuangan yang telah di audit oleh akuntan publik kewajarannya lebih dapat dipercaya dibandingkan laporan keuangan yang tidak atau belum di audit.Para pengguna laporan audit mengharapkan bahwa laporan keuangan yang telah diaudit oleh akuntan publik bebas dari salah saji material, dapat dipercaya kebenarannya untuk dijadikan sebagai dasar pengambilan keputusan dan telah sesuai dengan prinsip - prinsip akuntansi yang berlaku di Indonesia. Oleh karena itu diperlukan suatu jasa profesional yang independen dan objektif (yaitu akuntan publik) untuk menilai kewajaran laporan keuangan yang disajikan manajer.Terdapat beberapa ancaman terhadap independensi yang dapat mempengaruhi keputusan audit, dan berperan mengurangi kualitas audit dimana akan berdampak pada pelaporan keuangan yang tidak tepat (Kerler dan Brandon, 2010). Temuan pelaporan keuangan yang tidak tepat dapat mempengaruhi para stakeholder, seperti mengurangi minat kreditor, hilangnya reputasi auditor dan kesulitan untuk mengembalikan kepercayaan investor (Johnstone et al., 2001).

Kadous, Kennedy dan Peecher. (2003) meneliti peran komitmen untuk tujuan yang terarah pada keputusan audit yang ambigu. Mereka menemukan bahwa komitmen auditor untuk mendukung metode pilihan yang disukai klien dapat mempengaruhi keputusan auditor mengenai penerimaan metode pilihan klien. Auditor dengan tingkat Goal Commitment yang lebih tinggi sangat memungkinkan untuk menerima metode pilihan yang disukai klien.Tanggung jawab auditor melebihi kepatuhan menyertakan penilaian kualitas atau kesesuaian metode akuntansi klien akan meningkatkan 
obyektivitas auditor, sehingga mengurangi kesediaan auditor untuk mengizinkan klien menggunakan metode pilihan mereka, yaitu metode pelaporan yang agresif (Advisory Panel on Auditor Independence, 1994). Pada umumnya, beberapa metode akan meningkatkan keuntungan bersih dan/atau likuiditas, namun metode ini merupakan metode yang paling menguntungkan dalam keadaan tertentu seperti perjanjian hutang, target laba dan trend kinerja (Hackenbrack dan Nelson, 1996).

Salah satu insentif yang paling sering disebut dapat mempengaruhi keputusan auditor adalah ketergantungan ekonomi auditor terhadap klien yang secara khusus dibahas dalam istilah pendapatan dari jasa audit dan/atau jasa non-audit (Firth, 1980, Farmer et al., 1987; Chang dan Hwang, 2003). Meski masih diperdebatkan, namun Lord (1992) dan Chang dan Hwang (2003) mendukung bahwa auditor akan lebih menyetujui tekanan atau permintaan dari klien. Hubungan antara insentif auditor dan keputusan auditor merupakan penyebab keprihatinan, karena hal tersebut mengimplikasikan bahwa auditor mungkin mengizinkan klien menggunakan metode pelaporan agresif ketika auditor memiliki insentif yang cukup untuk melakukannya (Publik Oversight Board, 1994). Namun, Kerler dan Brandon (2010) menemukan bahwa client importance tidak mempengaruhi goal commitmentauditor untuk menerima metode pilihan klien, namun goal commitment berpengaruh secara positif terhadap penerimaan auditor atas metode pilihan klien.

Pemberian konsekuensi secara ekonomi kemungkinan dapat membuat Kantor Akuntan Publik dan auditor enggan menerima praktik pelaporan agresif klien (Chang dan Hwang, 2003). Lingkungan litigasi yang berlaku dalam suatu lingkungan tertentu mempunyai hubungan yang signifikan terhadap kebijakan diskresioner manajer dalam melaporkan keuangannya (Ball et al., 1999). Manajer akan melakukan penyeimbangan antara kos litigasi yang akan timbul dengan keuntungan yang akan diperoleh karena akuntansi yang agresif (Juanda, 2007). Zhang (1999) membuktikan bahwa kemungkinan seorang auditor membuat keputusan dalam membantu klien dapat bergantung pada kemungkinan dari penuntutan auditor ke dalam kasus kegagalan audit. Masalah mengenai pengaruh lingkungan litigasi yang mempengaruhi keputusan auditor menarik untuk diteliti karena terkait disahkannya UndangUndang No. 5 Tahun 2011 tentang Akuntan Publik antara lain dinyatakan ancaman hukuman bagi auditor apabila lalai. Kelalaian auditor pada umumnya disebabkan ketidakmampuan auditor memberikan opini yang tepat pada suatu laporan keuangan (Mayangsari, 2005). Peneliti sebelumnya (Hwang dan Chang, 2010) hanya menguji pengaruh lingkungan litigasi terhadap auditor di negara Amerika Serikat dan Hongkong yang notabene memiliki keadaan litigasi berbeda dengan negara Indonesia.

Faktor lain yang mempengaruhi penerimaan auditor adalah kepercayaan., akibatadalah hubungan interpersonal yang mungkin terbentuk antara auditor dan klien yang berpotensi merusak independensi auditor. Faktor kepercayaan dapat menggantikan skeptisme terhadap profesi auditor (Latham, Jacobs \& Roush, 1998dalam Kerler dan Brandon 2010). Pada kenyataannya auditor membangun kepercayaan dalam manajemen klien dan kepercayaan ini mungkin, dalam beberapa keadaan, dapat mempengaruhi penilaian risiko audit (Kerler \&Killough, 2009). Kepercayaan termasuk dalam kelompok ancaman Familiarity (or trust) threats menurut ISB (2000).Dalam konteks audit, kompetensi kepercayaan adalah keyakinan auditor mengenai kemampuan klien untuk membuat keputusan manajemen dan menyiapkan laporan keuangan mereka yang akurat, sementara goodwill trust adalah keyakinan auditor dalam "manajemen untuk mengkompilasi laporan keuangan perusahaan secara akurat dan menyediakan semua informasi yang relevan auditor perlu 
mengevaluasi kewajaran laporan keuangan klien" (Kerler \& Killough, 2009, hal.111).

$\mathrm{Di}$ Indonesia, peristiwa penuntutan akuntan publik di pengadilan oleh pemakai laporan akuntan yang merasa dirugikan masih jarang sekali terjadi. Oleh karena itu, masih sulit diketahui bagaimana anggapan masyarakat atas tanggung jawab akuntan publik dalam hal penemuan adanya kecurangan dalam perusahaan yang diperiksanya. Meskipun demikian, untuk pengembangan profesi akuntan publik di Indonesia, seharusnya para akuntan publik menyadari bahwa kecurangan yang dilakukan oleh manajemen menyebabkan kerugian yang besar bagi masyarakat.Terbitnya Undang undang No. 05 Tahun 2011 dikarenakan kasus yang terjadi pada Akuntan Publik di Indonesia sudah semakin banyak. Diantaranya, tahun 2009 PT. Waskita Karya (Persero), Tbk, diduga melakukan rekayasa laporan keuangan. Terbongkarnya kasus ini berawal saat pemeriksaan kembali neraca dalam rangka penerbitan saham perdana tahun 2008. Direktur Utama Waskita yang baru, M. Choliq yang sebelumnya menjabat Direktur Keuangan PT. Adhi Karya (Persero) Tbk, menemukan pencatatan yang tidak sesuai, dimana ditemukan kelebihan pencatatan $R p$ 400 miliar. Direksi periode sebelumnya diduga melakukan rekayasa keuangan sejak tahun buku 2004-2008 dengan memasukkan proyeksi pendapatan proyek multitahun ke depan sebagai pendapatan tahun tertentu. Kasus ini disebut-sebut sebagai Enron-nya Indonesia karena terdapat potensi pihak manajemen bekerja sama dengan pihak auditor eksternal. Namun demikian, pihak auditor hanya dikenakan sanksi berupa pembekuan izin usaha bukan penuntutan hukum ke pengadilan.

Tujuan penelitian ini adalah untuk menguji pengaruh Goal Commitment, lingkungan litigasi, dan kepercayaan terhadap penerimaan auditor atas metode pilihan klien. Penelitian ini merupakan modifikasi dari penelitian Kerler dan Brandon (2010), Chang dan Hwang (2010), serta Kerler dan
Killough (2009).Perbedaan penelitian ini dengan peneliti terdahulu ada pada negara yang di teliti, dimana para peneliti terdahulu melakukan penelitian di Amerika Serikat dan Hong Kong. Terbitnya Undang - undang No. 05 Tahun 2011 tentang Akuntan Publik, melatar belakangi mengapa penelitian ini dilakukan di Indonesia dimana peneliti ingin membuktikan apakah terbitnya Undang- undang tersebut mempengaruhi auditor di Indonesia dalam mengambil keputusan.

\section{Tinjauan pustaka dan pengembangan hipotesis}

\section{Goal Theory}

Teori ini mula-mula dikembangkan oleh Edwin A. Locke (1968).Menurut tori ini, perilaku seseorang ditentukan oleh dua macam kesadaran yaitu nilai dan tujuan. Nilai merupakan apa yang dihargai seseorang sebagai upaya mendapatkan kemakmuran (welfare). Seseorang yang telah menentukan goal atas perilakunya di masa depan maka goal tersebut akan mempengaruhi perilaku yang sesungguhnya. Teori ini juga menyatakan bahwa perilaku individu diatur oleh ide (pemikiran) dan niat seseorang. Sasaran dapat dipandang sebagai tujuan/tingkat kinerja yang ingin dicapai oleh individu. Jika seorang individu berkomitmen dengan tujuan tertentu, maka hal ini akan mempengaruhi tindakannya dan mempengaruhi konsekuensi kinerjanya.

\section{Goal Commitment}

Goal merupakan pusat perlakuan yang pada umumnya digunakan untuk motivasi kerja dan goal commitment merupakan konstruk yang penting dalam memahami suatu hubungan antara tujuan dan kinerja (Klein et al., 2001). Menurut Locke dan Latham (1990) goal commitment didefinisikan sebagai ketetapan hati seseorang untuk mencapai tujuan. Sementara menurut Hallenback dan Klein (1987) goal commitment menunjukkan luasnya usaha terhadap pencapaian tujuan, kerasnya dalam mengusahakan tujuan tersebut 
sepanjang waktu dan tidak adanya keinginan untuk mengurangi atau meninggalkan tujuan.

Arah tujuan, sampai pada suatu kesimpulan tertentu, dapat membiaskan penilaian individu dan proses pengambilan keputusan (Kunda, 1999 dalam Kerler dan Brandon 2010). Target tersebut dapat membiaskan informasi (atau bukti) yang dikumpulkan di proses penalaran, pengolahan informasi, dan cara di mana informasi tersebut digabungkan untuk mendukung kesimpulan yang disukai (misalnya Ditto \& Lopez, 1992; Lundgren \& Prislin,1998 dalam Kerler dan Brandon 2010).

Auditor memiliki arah tujuan dalam mendukung pilihan metode yang klien sukai (misalnya Hackenbrack \& Nelson, 1996; Haynes, Jenkins \& Nutt,1998 dalam Kerler dan Brandon 2010). Sementara tujuan langsung bisa membiaskan penilaian individu, mereka tidak buta terhadap realitas yang ada (Kunda, 1999 dalam Kerler dan Brandon 2010). Hal tersebut didukung oleh temuan yang menyatakan auditor lebih mungkin untuk menerima pilihan posisi klien ketika pedoman yang ada bersifat ambigu mengenai perlakuan akuntansi yang sesuai (misalnyaTrompeter, 1994; Nelson \& Kinney, 1997; Salterio \& Koonce, 1997;Braun, 2001; Hronsky \& Houghton, 2001 dalam Kerler dan Brandon 2010; Kadous, et al. 2003).

$$
\text { Penelitian sebelumnya }
$$

menunjukkan bahwa insentif seperti client importance dan kepercayaan dapat merusak independensi dan paling mungkin mempengaruhi keputusan audit di bagian-bagian yang paling membutuhkan penilaian dan pertimbangan (Johnstone et al, 2001; Bazerman et al., 2002; Kerler dan Brandon, 2010). Kadous et al. (2003) menyelidiki peran komitmen pada arah tujuan auditor dalam keputusan audit ambigu. Auditor berkomitmen pada tujuan yang mengarah untuk mendukung metode pilihan klien dapat mempengaruhi keputusan auditor tersebut mengenai penerimaan metode pilihan klien. Penelitian tersebut menunjukkan bahwa suatu konklusi yang diambil dapat dibenarkan, auditor dengan tingkat goal commitment yang lebih tinggi akan cenderung menerima pilihan metode akuntansi klien. Sehingga dugaan hipotesis pertama yang sudah diteliti sebelumnya oleh peneliti terdahulu Kerler dan Brandon (2010) adalah:

$\mathbf{H}_{1}$ : Goal commitment berpengaruh positif terhadap penerimaan auditor atas metode pilihan klien.

\section{Lingkungan Litigasi}

Penerapan prinsip-prinsip akuntansi yang hanya mendasarkan pada standar akuntansi tidak bisa dijamin efektivitasnya bila tidak ada mekanisme lingkungan yang memperkuat penerapan tersebut.Lebih jauh, standar akuntansi yang merupakan mekanisme lingkungan peraturan (regulatory environment), penerapannya tidak bisa efektif bila tidak diperkuat oleh mekanisme lingkungan litigasi (litigation environment). Lingkungan hukum merupakan unsur yang memperkuat efektivitas pelaksanaan standar, karena di dalamnya terkandung konsekuensi ancaman litigasi bagi perusahaan (Juanda,2007). La Porta et al., (1998) dan Ball et al., (2003) menyatakan bahwa sistem hukum, hak-hak shareholder dan praktik pelaporan keuangan kemungkinan berbeda dari satu yuridiksi dengan yuridiksi lainnya. Faktor-faktor ini, kemungkinan mempengaruhi lingkungan profesi di mana auditor bekerja (DeFond dan Francis, 2005).

Pelaporan keuangan agresif merupakan metode akuntansi yang dipilih klien untuk menggambarkan kondisi keuangan yang lebih favorable daripada kondisi yang sebenarnya (Hwang dan Chang, 2010). Apabila auditor menerima pilihan pelaporan keuangan agresif tersebut dan kemudian klien mengalami kesulitan keuangan sesudahnya misalnya kebangkrutan, auditor akan menyingkapkan diri mereka pada kasus litigasi apabila para stakeholderdapat membuktikan terdapat hubungan antara kerugian yang dialami dengan pelaporan agresif dalam laporan keuangan (Hwang dan Chang, 2010). Namun demikian, 
kemungkinan stakeholder menyimpan perkara hukumnya melawan auditor dan kemungkinan keberhasilan stakeholder tersebut tergantung pada lingkungan litigasi dimana auditor melakukan pekerjaan (Hwang dan Chang, 2010).Semakin ketat tingkat litigasi, stakeholder lebih mungkin membawa masalah dengan auditor ke pengadilan. Sehingga, auditor akan sedikit mungkin menyetujui perlakuan akuntansi agresif yang dipilih klien karena konsekuensi hukum dan ekonomi yang akan dihadapi (Hwang dan Chang, 2010). Di sisi lain, terdapat sedikit dorongan bagi stakeholder untuk menghadapi auditor di pengadilan apabila hal tersebut sulit dan membutuhkan banyak biaya.

$$
\text { Undang-Undang }
$$

Republik Indonesia No. 5 Tahun 2011 yang mengatur tentang Profesi Akuntan Publik, dimana dalam Pasal 55 dinyatakan bahwa:

Akuntan publik yang:

a. Melakukan

membantu

manipulasi,

manipulasi, melakukan dan/atau memalsukan data yang berkaitan dengan jasa yang diberikan sebagai mana dimaksud dalam Pasal 30 ayat (1) huruf $\mathrm{j}$; atau

b. Dengan sengaja melakukan manipulasi, memalsukan, dan/atau menghilangkan data atau catatan pada kertas kerja atau tidak membuat kertas kerja yang berkaitan dengan jasa yang diberikan sebagaimana dimaksud dalam Pasal 3 ayat (1) sehingga tidak dapat digunakan sebagaimana mestinya dalam rangka pemeriksaan oleh pihak yang berwenang dipidana dengan pidana penjara paling lama 5 (lima) tahun dan pidana denda paling banyak $\mathrm{Rp}$ $300.000 .000,00$ (tiga ratus juta rupiah).

Lingkungan litigasi di Indonesia dapat dikatakan menjadi ketat setelah disahkannya ketentuan UndangUndang No. 5 tentang Akuntan Publik tersebut. Chang dan Hwang (2010) menyatakan bahwa lingkungan litigasi diduga memiliki hubungan negatif dengan penerimaan auditor atas metode pilihan klien. Sehingga dugaan hipotesis kedua penelitian iniadalah:

$\mathbf{H}_{2}$ : Lingkungan litigasi berpengaruh negatif terhadap penerimaan auditor atas metode pilihan klien.

\section{Kepercayaan}

Hubungan interpersonal yang berkembang antara auditor dan klien mengemukakan bahwa sebagai obligasi berkembang, kepercayaan dapat menggantikan skeptisisme profesional auditor (e.g. Latham, Jacobs \& Roush, 1998 dalam Kerler dan Brandon, 2010). Auditor pada kenyataannya mengembangkan kepercayaan dalam manajemen klien dan kepercayaan ini mungkin dalam beberapa keadaan mempengaruhi penilaian resiko audit dan peran pengembangan kepercayaan auditor dalam manajemen klien bermain di penilaian audit (Kerler dan Killough, 2009). Auditor yang mengembangkan kepercayaan dalam manajemen klien lebih berkomitmen untuk menerima keputusan pelaporan klien (Kerler dan Brandon, 2010).

Ancaman lain terhadap kualitas audit adalah hubungan interpersonal yang mungkin terbentuk antara auditor dan klien yang mungkin berpotensi merusak independensi auditor. Penelitian ini menguji apakah kepercayaan dikembangkan dari hubungan ini pada akhirnya akan mempengaruhi pertimbangan auditor. Kerangka kepercayaan Nooteboom (1996), kepercayaan individu dalam orang atau kelompok lain terdiri dari dua dimensi : Kepercayaan kompetensi yang mengacu pada kemampuan individu untuk melakukan dan kepercayaan goodwill yang mengacu pada niat individu untuk melakukan (hal. 990). Kerler dan Killough (2009) menyelidiki faktor apa yang mempengaruhi auditor terhadap kepercayaan klien dalam situasi tertentu.

Penelitian terdahulu menemukan bahwa karakteristik dari situasi dan lingkungan (misalnya lama interaksi, kualitas komunikasi, dan kerjasama dari klien) mempengaruhi kepercayaan 
auditor di klien.Kerler dan Killough (2009), menggunakan skala dikembangkan untuk mengukur kepercayaan goodwill auditor dalam manajemen klien, dan menemukan bahwa auditor melakukan pengembangan kepercayaan dalam manajamen klien sebagai akibat dari interaksi masa lalu. Selanjutnya, mereka menemukan kepercayaan yang dapat mempengaruhi auditor dari keseluruhan penilaian resiko penipuan setelah pengalaman tidak memuaskan dengan manajemen klien. Secara keseluruhan, hasil penelitian Kerler dan Killough (2009) menunjukkan bahwa penilaian integritas auditor dan keputusan mungkin dipengaruhi oleh kepercayaan mereka dalam manajemen klien. Untuk menguji hipotesis ini dalam klien audit akan meningkat komitmen auditor untuk mendukung metode yang disukai klien. Sehingga dugaan hipotesis ketiga penelitian ini yang telah diteliti oleh peneliti terdahulu Kerler dan Killough (2009) adalah :

$\mathbf{H}_{3}$ : Kepercayaan berpengaruh negatif terhadap penerimaan auditor atas metode pilihan klien.

\section{Metode Pilihan Klien (Client- Preferred Method)}

Prinsip Akuntansi Berterima Umum (PABU) merupakan batasan dalam praktik akuntansi yang dapat membedakan antara manajemen laba dan penipuan atau kecurangan akuntansi yang dilakukan oleh manajemen. Ada berbagai pilihan metode akuntansi yang dapat diterapkan oleh manajemen sesuai dengan motivasinya, dari akuntansi yang konservatif hingga yang penipuan atau kecurangan akuntansi. Pilihan-pilihan metode tersebut dapat dikelompokkan dalam dua kategori, yaitu metode yang masih dalam kerangka prinsip akuntansi berterima umum. Akuntansi konservatif, laba netral dan akuntansi agresif merupakan pilihan metode yang masih dalam kerangka PABU yang dapat diterapkan manajemen dalam menyajikan laporan keuangan kepada pihak-pihak ekstern (Suhendro, 2006).
Dalam pelaporan yang agresif, manajemen menggunakan kebijakankebijakan akuntansi agresif yang pada akhirnya manajemen dapat dikatakan melakukan manipulasi laba atau meningkatkan laba dari jumlah yang sebenarnya. Tindakan ini ditujukan untuk memaksimumkan utilitas manajer dan cenderung untuk menguntungkan manajer dengan cara mempengaruhi proses pelaporan keuangan. Peneliti-peneliti sebelumnya seperti Heckenbrack dan Nelson (1996), Chang dan Hwang (2003) serta Kadous et al. (2003) mendefinisikan pelaporan agresif klien sebagai sebuah metode pelaporan yang diadopsi oleh klien dan diterima oleh auditor yang menggambarkan kondisi keuangan klien berbeda atau tidak sesuai dengan kondisi yang ada.

\section{Keputusan Audit (Penerimaan Auditor)}

Keputusan audit dipengaruhi oleh komitmen pada arah yang bertujuan untuk mendukung metode akuntansi pilihan klien. Pengguna laporan keuangan akan berusaha untuk menafsirkan, dan memproses informasi sendiri, sehingga kemungkinan kesimpulan yang diambil akan menjadi bias (Kadous et al., 2003). Sebagaimana dinyatakan sebelumnya bahwa arah tujuan auditor dapat membuat informasi (bukti) menjadi bias dalam proses penalaran, kedalaman pengolahan informasi, dan cara di mana informasi ini dikombinasikan dalam keputusan untuk mendukung konklusi yang dipilih (Ditto dan Lopez, 1992; Lundgren dan Prislin, 1998 dalam Kerler dan Brandon 2010).

Insentif (misalnya kepentingan klien, kepercayaan, dll) dapat merusak independensi dan paling mungkin mempengaruhi audit di bagian-bagian yang paling membutuhkan penilaian (Johnstone et al, 2001 dalam Kerler dan Brandon 2010 dan Bazerman, dkk, 2002).Auditor akan cenderung memberikan dukungan bagi metode akuntansi pilihan kliendan berkomitmen dalam tujuan yang mengarah untuk menerima posisi yang lebih disukai oleh klien lebih dari pada mengikuti

standar 
audit.dan(Hackenbrack dan Nelson, 1996; Kadous et al, 2003). lingkungan litigasi mempunyai pengaruh signifikan terhadap keputusan auditor untuk mengikuti pilihan metode akuntansi yang dipilih oleh klien (Hwang dan Chang, 2010)

\section{Metode penelitian \\ Populasi dan Sampel}

Populasi penelitian ini adalah auditor yang bekerja di Kantor Akuntan Publik (KAP) di wilayah DKI Jakarta yang terdaftar dalam direktori KAP tahun 2012.Nama dan alamat KAP diambil dari Direktori KAP Regional Jakarta yang diterbitkan oleh Ikatan Akuntan Publik Indonesia tahun 2012. Alasan penentuan KAP di wilayah DKI Jakarta karena berdasarkan Direktori Ikatan Akuntan Publik Indonesia 44,71\% KAP di Indonesia berada di DKI Jakarta sehingga diharapkan dapat menunjukkan generalisasi keadaan di Indonesia dan sampel dalam penelitian ini. Sampel penelitan adalah Auditor yang bekerja di KAP wilayah Sudirman dan Kuningan DKI Jakarta

\section{Teknik Pemilihan Sampel}

Teknik penarikan sampel melalui purposive sampling methode, dengan kriteria : (1) auditor yang bekerja di Kantor Akuntan Publik yang terdaftar di IAPI; (2) auditor mulai dari tingkatan junior, senior, supervisor, dan manajer yang mempunyai pengalaman kerja di atas satu tahun dengan mempertimbangkan auditor yang sudah memiliki pengalaman diatas satu tahun dapan merespon penelitian ini; (3) auditor pelaksana yang bekerja di KAP menengah ke atas dimana diprediksikan memiliki jumlah auditor dengan pengalaman lebih banyak mengaudit dibandingkan KAP menengah ke bawah.

\section{Jenis, Sumber, dan Teknik Pengumpulan Data}

Data penelitian ini adalah data primer yang diperoleh melalui penyebaran kuesioner Dengan mendatangi langsung responden (Auditor di KAP ) atau melaluisurat (mail survey).

Setiap KAP tidak diketahui pasti jumlah auditornya sehingga setiap KAP diberi beberapa kuesioner untuk auditor yang bekerja di KAP tersebut, penyebaran kuesioner yang bersamaan dengan masa sibuk auditor dalam mengaudit laporan keuangan, yaitu Desember hingga April sementara jumlah responden yang dibutuhkan sebagai sampel adalah lebih dari 100 karena penelitian ini menggunakan model Structural Equation Modeling (SEM), sehingga kuesioner yang disebar sebanyak 150 kuesioner dengan pertimbangan kemungkinan adanyasejumlah kuesioner yang tidak kembali karena response rate auditor yang rendah.

\section{Operasionalisasi Variabel}

Sesuai dengan rumusan hipotesis penelitian, maka variabel-variabel penelitian ini dapat dilihat pada tabel berikut :

Tabel 1.

Operasional Variabel

\begin{tabular}{|c|c|c|c|}
\hline Variabel & Definisi Variabel & Indikator & Skala \\
\hline $\begin{array}{l}\text { Variabel Eksogen (X) : } \\
\text { 1. Goal Commitment }\end{array}$ & 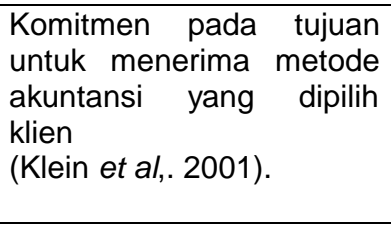 & $\begin{array}{l}\text { 1.Keseriusan } \\
\text { 2.Persepsiuntuk tujuan } \\
\text { 3.Komitmen kuat } \\
\text { 4.Kepedulian } \\
\text { 5.Mengabaikan tujuan } \\
\text { (Klein et al,. (2001). }\end{array}$ & Ordinal \\
\hline 2.Lingkungan Litigasi & $\begin{array}{l}\text { Kondisi legal atau litigasi } \\
\text { yang mempengaruhi } \\
\text { pertimbangan, keputusan } \\
\text { audit dan penerimaan } \\
\text { auditor atas metode } \\
\text { pilihan klien (Pelaporan } \\
\text { Agresif) (Hwang dan } \\
\text { Chang, 2010). }\end{array}$ & $\begin{array}{l}\text { Pengaruh ketentuan tentang } \\
\text { profesi akuntan publik } \\
\text { (Undang-Undang No.05 Tahun } \\
2011 \text { tentang Akuntan Publik). }\end{array}$ & Ordinal \\
\hline 3.Kepercayaan & Hubungan interpersonal & 1.Keyakinan niat baik & Ordinal \\
\hline
\end{tabular}




\begin{tabular}{|c|c|c|c|}
\hline & 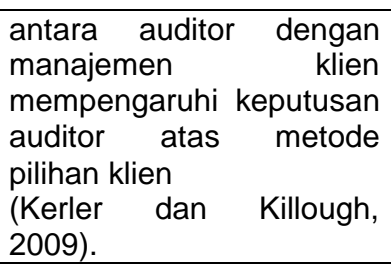 & $\begin{array}{l}\text { klien } \\
\text { 2. Motif } \\
\text { 3. Menolong } \\
\text { 4. Ketergantungan } \\
\text { 5. Likability } \\
\text { (Kemampuan) } \\
\text { (Kerler dan Killough, 2009). }\end{array}$ & \\
\hline $\begin{array}{l}\text { Variabel Endogen }(\mathbf{Y}) \text { : } \\
\text { 1.Penerimaan Auditor } \\
\text { atas Metode Pilihan } \\
\text { Klien }\end{array}$ & $\begin{array}{l}\text { Menerima metode yang } \\
\text { dipilih klien pada } \\
\text { pengakuan pendapatan } \\
\text { dalam laporan keuangan } \\
\text { (Kerler dan Brandon, } \\
\text { 2010). }\end{array}$ & $\begin{array}{l}\text { Tingkat agresif Klien dalam } \\
\text { penyusunan laporan keuangan } \\
\text { (Kerler dan Brandon, 2010) }\end{array}$ & Ordinal \\
\hline
\end{tabular}

\section{Metode Analisis Data}

Analisis data dalam penelitian ini adalah persamaan regresi berganda dengan analisis Multivariate Structure Equation (SEM)menggunakan program AMOS 21.0

Persamaan regresi ini digunakan untuk menggambarkan hubungan linear antara variabel dependen (endogen) $\mathrm{Y}$ dan variabel-variabel (eksogen) atau sering juga disebut explanatory, causal atau predictor $\mathrm{X} 1$, X2, X3. Secara matematis persamaan regresinya dapat dituliskan sebagai berikut:

$Y=\alpha+\beta 1 G C+\beta 2 L L+\beta 3$ TRUST $+e$

Dimana

$\mathrm{Y}=$ Penerimaan Auditor atas Metode Pilihan Klien (CPM)

$$
\begin{array}{ll}
\mathrm{GC} & =\text { Goal Commitment } \\
\mathrm{LL} & =\text { Lingkungan Litigasi } \\
\mathrm{TRUST} & =\text { Kepercayaan } \\
\beta 1 & =\text { Koefisien variable }
\end{array}
$$

independen Goal Commitment

B2 $=$ Koefisien variable independen Lingkungan Litigasi

B3 $=$ Koefisien variable independen Kepercayaan

$\alpha=$ Konstansta

e $=$ error

\section{HASIL PENELITIAN DAN PEMBAHASAN}

\section{Gambaran Umum Responden}

Responden penelitian ini adalah Auditor yang bekerja di Kantor Akuntan Publik kawasan Sudirman dan Kuningan DKI Jakarta.Melalui pengiriman kuesioner sebanyak 150
kuesioner.Dari 150 kuesioner yang disebar, kuesioner yang diisi dan dikembalikan adalah sejumlah 116 kuesioner dengan tingkat respon rate sebesar $77.33 \%$.Kuesioner yang dikembalikan tapi tidak diisi lengkap 2 kuesioner dan yang tidak sesuai dengan kriteria adalah 5 kuesioner.Kuesioner yang tidak kembali disebabkan responden tengah dalam kesibukan sehingga tidak sempat untuk menjawab kuesioner, dimana penyebaran kuesioner pada bulan Desember - Maret ini merupakan season pack bagi para auditor.Oleh karena itu, jumlah data yang dapat diolah untuk analisis adalah sejumlah 109 kuesioner. Rincian kuesioner, responden dan gambaran umum responden secara keselutuhan disajikan pada Tabel-tabel (table 2, 3, 4) berikut ini :

\section{Hasil Analisis Data Mengidentifikasi Model}

Analisis SEM hanya dapat dilakukan apabila hasil identifikasi model menunjukan bahwa model termasuk dalam kategori over-identified. Identifikasi ini dilakukan dengan melihat nilai $d f$ dari model yang dibuat. Table 5 adalah hasil output AMOS yang menunjukan nilai $d f$ model sebesar 98. Hal ini mengindikasikan bahwa model termasuk kategori overidentified karena memiliki nilai $d f$ positif. Oleh karena itu, analisis data bisa dilanjutkan ke tahap berikutnya.

\section{Mengevaluasi Estimasi Model}

a. Asumsi Kecukupan Sampel Jumlah sampel dalam penelitian ini adalah sebanyak responden, jumlah sampel tersebut dinilai telah 
memenuhi kriteria jumlah sampel minimal, sesuai dengan ketentuan yang disyaratkan untuk analisis data menggunakan Struktural Equation Modeling (SEM) (Hair et al., 1998). Jumlah tersebut mencukupi sebagai ukuran sampel untuk kepentingan analisis.

b. Asumsi Normalitas

Uji normalitas dilakukan terhadap data yang digunakan dalam analisis model awal secara keseluruhan, dengan menggunakan AMOS 21.0. menyajikan nilai minimum, maksimum, skewness, kurtosis, critical ratio untuk masing-masing variabel dan total nilai multivariate.

Model Pengukuran (Measurement Model) dengan Analisis konfirmatori Model pengukuran (Measurement Model) dengan analisis konfirmatori dilakukan pada konstruk eksogen dan endogen, untuk menyelidiki unidimensionalitas dari indikatorindikator yang menjelaskan sebuah faktor atau sebuah variabel.

\section{Goodness of Fit Analysis}

Hasil pengukuran goodness of fit model mengindikasikan bahwa model yang diajukan dapat diterima (Tabel $6,7,8,9,10)$. Hal ini dapat dilihat dari nilai probabilitas, juga dari kriteria fit yang lain yaitu GFI, AGFI, CFI, TLI, dan RMSEA, apabila salah satu dari kriteria fit lolos maka goodness of fit di anggap dapat diterima (Selnes, 1998; Ghozali, 2005).

Normed Chi-Square (CMIN/DF) adalah ukuran yang menunjukkan indeks kesesuaian parsimoni yang mengukur hubungan goodness of fit model dengan jumlah koefisien estimasi yang diharapkan untuk mencapai tingkat kesesuaian. Nilai CMIN/DF pada model ini adalah 1.732 menunjukkan bahwa model penelitian ini termasuk kriteria baik karena nilai CMIN/DF pada penelitian ini $<2$ (Ghozali, 2008).

GoodnessofFit Index (GFI) menunjukkan tingkat kesesuaian model secara keseluruhan yang dihitung dari residual kuadrat dari model yang diprediksi dibandingkan data yang sebenarnya. Nilai yang mendekati 1 mengisyaratkan model yang diuji memiliki kesesuaian yang baik.Dengan tingkat penerimaan yang direkomendasikan $\geq 0.90$ dapat disimpulkan bahwa model penelitian ini memiliki tingkat kesesuaian yang belum cukup baik dengan nilai GFI sebesar 0.852 .

\section{Adjusted Goodnessoffit Index (AGFI)}

Adjusted Goodnessoffit Index (AGFI) adalah GFI yang disesuaikan dengan rasio antara degree of freedom dari model yang diusulkan dan degree of freedom dari null model.Nilai AGFI yang direkomendasikan adalah $\geq$ 0.90.dapat dilihat pada tabel 8.Nilai AGFI dalam model ini adalah 0.795 yang menunjukkan bahwa model dinilai belum cukup baik.

Tucker Lewis Index (TLI) adalah indeks kesesuaian incremental yang membandingkan model yang diuji dengan baseline model.TLI merupakan indeks kesesuaian model yang kurang dipengaruhi oleh ukuran sampel.Nilai yang direkomendasikan $\geq 0.90$. Dalam model ini dapat disimpulkan bahwa model menunjukkan tingkat kesesuaian yang baik dengan nilai TLI sebesar 0.944.(Tabel 8).

\section{Comparative Fit Index (CFI)}

Comparative Fit Index (CFI) adalah indeks kesesuaian incremental yang membandingkan model yang diuji dengan null model. Besaran indeks ini dalam rentang 0 sampai 1 dan nilai yang mendekati 1 mengindikasikan model memiliki tingkat kesesuaian yang baik. Indeks ini sangat dianjurkan untuk dipakai karena indeks ini relatif tidak sensitif dengan besarnya sampel dan kurang dipengaruhi oleh kerumitan model. Dengan memperhatikan nilai yang direkomendasikan yaitu $\geq 0.90$. Dalam model ini nilai CFI sebesar 0.954 menunjukkan bahwa model ini memiliki kesesuaian yang baik.

Root Mean Square Error of Approximation (RMSEA) adalah indeks yang digunakan untuk mengkompensasi nilai Chi-Square dalam sampel yang besar. Nilai penerimaan yang direkomendasikan < 0.08 dan $>0,04$; nilai RMSEA model sebesar 0.08 menunjukkan tingkat kesesuaian yang baik.(Tabel 9). 


\section{Efek Goal Commitment terhadap Penerimaan Auditor Atas Metode Pilihan Klien}

Berdasarkan tabel 10. dapat dilihat bahwa goal commitment(GC) berpengaruh positif padapenerimaan auditor atas metode pilihan klien, hal ini ditunjukan dengan nilai koefisien standardized 0.109, dengan nilai critical ratio (CR) 2,806 dan nilai $p$ value0,05. Nilai $\mathrm{CR}$ tersebut tidak berada diantara nilai kritis \pm 1.96 , dengan demikian hipotesis pertama diterima yaitu goal commitment (GC) berpengaruh positif terhadap penerimaan auditor atas metode pilihan klien sesuai dengan penelitian Kerlen dan Brandon (2010).

Hasil penelitian ini sejalan dengan penelitian Kadous (2003), yang menyatakan bahwa komitmen tujuan auditor akan mempengaruhi penerimaan mereka untuk menerima metode pilihan klien. Pilihan metode yang diambil klien tidak selalu merupakan metode yang tepat untuk dipakai, mengingat kondisi perusahaan klien juga sebagai bahan pertimbangan.Auditor perlu lebih berkonsentrasi untuk memberikan jawaban jika ternyata metode yang dipilih klien tidak tepat agar memberikan perbaikan bagi perusahaan klien itu sendiri.

\section{Efek Lingkungan Litigasi Terhadap Penerimaan Auditor Atas Metode Pilihan Klien}

Berdasarkan tabel 10, dapat dilihat bahwa lingkungan litigasi (LL)berpengaruh negatif padapenerimaan auditor atas metode pilihan klien, hal ini ditunjukan dengan nilai koefisien standardized 0.093 , dengan nilai critical ratio (CR) -2,274 dan nilai $p$-value 0,023 . Nilai $\mathrm{CR}$ tersebut tidak berada diantara nilai kritis \pm 1.96 , dengan demikian hipotesis kedua diterima yaitu lingkungan litigasi (LL) berpengaruh negatifterhadap penerimaan auditor atas metode pilihan klien sesuai dengan penelitian Hwang dan Chang (2010).

Hasil penelitian ini konsisten dengan penelitian Hwang dan Chang (2010) yang menyatakan bahwa lingkungan litigasi mempengaruhi kesediaan auditor untuk menerima akuntansi agresif klien. Secara spesifik, auditor yang bekerja di lingkungan hukum yang ketat akan lebih konservatif dan cenderung kurang menerima praktik akuntansi agresif klien dibandingkan dengan auditor yang bekerja dengan tingkat litigasi yang rendah. Auditor di Indonesia umumnya menganggap bahwa penetapan Undang-Undang No. 5 tentang Akuntan Publik yang dalam salah satu pasalnya mengatur mengenai hukuman pidana membuat auditor baik dari tingkat auditor junior sampai tingkat manajer semakin bertindak hati-hati dalam mengambil keputusan audit. Hal ini mengindikasikan bahwa telah terdapat aturan hukum yang eksplisit bagi akuntan publik serta tingkat lingkungan litigasi di Indonesia bagi para akuntan publik sudah semakin tinggi dengan ditetapkannya undang-undang tersebut.

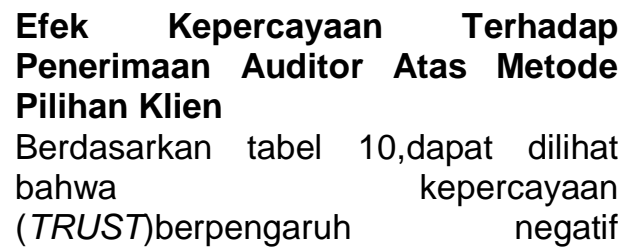
padapenerimaan auditor atas metode pilihan klien, hal ini ditunjukan dengan nilai koefisien standardized 0.088 , dengan nilai critical ratio (CR) -2.043 dan nilai $p$-value 0.041 . Nilai $C R$ tersebut berada diluar nilai kritis \pm 1.96 , dengan demikian hipotesis ketiga diterima yaitu kepercayaan (TRUST) berpengaruh terhadap penerimaan auditor atas metode pilihan klien namun hasil penelitian ini berbeda dengan hasil penelitian terdahulu Kerler dan Brandon (2010).

Hasil penellitian ini menunjukkan bahwa besarnya kepercayaan yang dimiliki oleh auditor kepada manajemen klien mempengaruhi mereka dalam menerima metode pilihan klien. Hasil penelitian ini sejalan dengan penelitian Kerler dan Killough (2009), yang menyatakan bahwa kepercayaan auditor kepada manajemen klien akan mempengaruhi komitmen tujuan mereka untuk menerima metode pilihan klien. Hasil ini mencerminkan bahwa auditor yang 
mengisi kuesioner tidak terlalu terpengaruh dengan hubungan baik dengan klien sehingga auditor percaya sepenuhnya terhadap kliennya. Hubungan baik antara auditor dengan klien akan sangat menunjang kelancaran selama proses audit berlangsung. Namun, kepercayaan berlebihan yang diberikan oleh auditor terbukti dalam penelitian ini dapat mempengaruhi independensi auditor. Oleh karena itu, perlu adanya batasan bagi auditor dalam mengembangkan hubungan interpersonalnya dengan klien agar tidak mempengaruhi keputusan audit yang akan diambil.

\section{Penutup \\ Simpulan}

Berdasarkan analisis dan pembahasan sebelumnya, maka dapat ditarik kesimpulan sebagai berikut:

1. Goal commitment berpengaruh positif terhadap penerimaan auditor atas metode pilihan klien, yang berarti bahwa komitmen tujuan auditor akan mempengaruhi penerimaan mereka untuk menerima metode pilihan klien. Pilihan metode yang diambil klien tidak selalu merupakan metode yang tepat untuk dipakai, mengingat kondisi perusahaan klien juga sebagai bahan pertimbangan. Auditor perlu lebih berkonsentrasi untuk memberikan jawaban jika ternyata metode yang dipilih klien tidak tepat agar memberikan perbaikan bagi perusahaan klien itu sendiri.

2. Lingkungan litigasi berpengaruh negatif terhadap penerimaan auditor atas metode pilihan klien. Secara spesifik, auditor yang bekerja di lingkungan hukum yang ketat akan lebih konservatif dan cenderung kurang menerima praktik akuntansi agresif klien dibandingkan auditor yang bekerja dengan tingkat litigasi yang rendah. Auditor di Indonesia umumnya menganggap bahwa penetapan Undang-Undang No. 5 tentang Akuntan Publik yang dalam salah satu pasalnya mengatur mengenai hukuman pidana, membuat auditor semakin berhati-hati dalam mengambil keputusan audit.

3. Kepercayaan berpengaruh negatif terhadap penerimaan auditor atas metode pilihan klien, berarti bahwa auditor tidak terlalu terpengaruh dengan hubungan baik dengan klien sehingga auditor percaya sepenuhnya terhadap kliennya. Hubungan baik antara auditor dengan klien akan sangat menunjang kelancaran selama proses audit berlangsung. Namun, kepercayaan berlebihan yang diberikan oleh auditor dapat mempengaruhi independensi auditor. Oleh karena itu, perlu adanya batasan bagi auditor dalam mengembangkan hubungan interpersonalnya dengan klien agar tidak mempengaruhi keputusan audit yang akan diambil.

\section{Saran}

Penelitian ini memiliki keterbatasan yang diharapkan dapat diperbaiki melalui penelitian serupa di masa mendatang, yaitu :

1. Diharapkan auditor selalu mempertahankan goal commitmentnya dalam mengambil keputusan audit atas metode pilihan klien agar tetap pada peraturan yang ada. Karena jika goal commitment pada auditor tidak berpengaruh, maka peraturan yang ada tidak lagi dilaksanakan sebagaimana mestinya, dan akan merugikan pengguna laporan audit tersebut.

2. Auditor harus lebih mengenal dan mengetahui tentang lingkungan litigasi dalam menjalankan profesinya. Jika auditor tidak memperhatikan peraturan tentang Akuntan Publik yang ada dalam UU No. 05 Tahun 2011, maka auditor akan mengambil keputusan tanpa memperhatikan hukum yang berlaku dan hal tersebut merugikan pengguna laporan audit.

3. Profesionalisme auditor harus tetap dijaga tanpa melihat hubungan yang terjalin dengan kliennya sehingga mempengaruhi 
keputusan auditor atas metode pilihan klien yang akan merugikan pengguna laporan audit.

4. Peneliti selanjutnya dapat memilih Responden mulai dari tingkatan auditor senior, dengan pertimbangan sudah mempunyai cukup pengalaman audit dan berkompeten, Meneliti auditor dari Kantor Akuntan Publik yang berada di luar wilayah DKI Jakarta untuk melihat apakah terdapat perbedaan terhadap penerimaan atas metode pilihan klien setelah ditetapkannya UU No. 5 tentang Akuntan Publik dan Menguji apakah terdapat faktor atau variabel lain yang dapat memotivasi auditor dalam mengambil keputusan audit guna memuaskan auditee (klien) misalnya client importance (Kerler dan Brandon, 2010).

\section{Referensi}

Advisory Panel on Auditor
Independence.
Strengthening 1994.
Professionalism of the
Independent Auditor. Stamford,
CT: Public Oversight Board.

Ball, R., Robin, A., Wu, J.S., 2003. Incentives versus standards: properties of accounting income in four East Asian Countries. Journal of Accounting and Economics 36, 235-270.

Bazerman, M. H., Loewenstein, G., dan Moore, D. A. 2002. Why good accountants do bad audits. Havard Business Review, 80(11), 96-102

Chang, C. J., dan Hwang, N. R. 2003. The impact of retention incentives and client business risks on auditors' decisions involving aggressive reporting practices. Auditing: A Journal of Practice \& Theory, 22(2), 207-218.

DeFond, M.L., dan Francis, J.R., 2005. Audit research after SarbanesOxley.
Auditing: A Journal of Practice and Theory 24 (Suppl.), 5-30.

Farmer, T. A., Rittenberg, L. E., dan Trompeter, G. M. (1987). An investigation of the impact Of economic and organizational factors on auditor independence. Auditing: A Journal of Practice \& Theory, 7(1), 1-14.

Firth, M. 1980. Perceptions of auditor independence and official ethical guidelines. The Accounting Review, 55(3), 451-466.

Ghozali, Imam. 2008.Model Persamaan Struktural Konsep dan Aplikasi dengan Program Amos 16.0. Semarang: Badan Penerbit Universitas Diponegoro.

Gujarati, D.1999. "Ekonometrika (Alih bahasa: Sumarno Zein)". Jakarta:PT.GeloraAksara ratama.

Hackenbrack, K., dan Nelson, M. W. 1996. Auditors' incentives and their application of financial accounting standards. The Accounting Review, 71(1), 43-59.

Hair, J.F. et al. 1998. Multivariate Data Analysis. New Jersey. PrenticeHall.

Hollenbeck, J. R., dan Klein, H. J. 1987. Goal Commitment and Goal-Setting Process: Problems, Prospects and Proposal for Future Research. Journal of Applied Psychology. Vol. 72, No.2, 212-220

Hudayati, Ataina. 2002. Perkembangan Penelitian Akuntansi Keprilakuan:Berbagai Teori dan Pendekatan yang Melandasi. JAAI Volume 6 No.2.

Hwang, N. R. dan Chang, C. J. 2010. Litigation environment and auditors' decisions to Accept clients' aggressive reporting. Auditing: Journal of Accounting Public Policy, 29, 281-295.

Juanda, Ahmad. 2007. Pengaruh Risiko Litigasi dan Tipe Strategi Terhadap Hubungan Antara Konflik Kepentingan Konservatisma Akuntansi. Universitas Muhamadiyah Malang. 
Johnstone, K. M., Sutton, M. H., dan Warfield, T. D. 2001. Antecedents and consequences of independence risk: Framework for analysis. Accounting Horizons, 15(1), $1-18$.

Kadous, K., Kennedy, S. J., dan Peecher, M. E. 2003. The effect of quality assessment and directional goal commitment on auditors' acceptance of clientpreferred accounting methods. The Accounting Review, 78(3), 759-778.

Kerler, W. A., III, dan Killough, L. N. 2009. The effects of satisfaction with a client's management during a prior audit engagement, trust, and moral reasoning on auditor's perceived risk of management fraud. Journal of Business Ethics, 85(2), 109-136.

Kerler, W. A., III, dan Brandon, D. M. 2010. The effects of trust, client importance, and goal commitment on auditors' acceptance of client-preferred methods. Advances in Accounting, incorporating Advances in International Accounting, 26, 246-258

Klein, H. J., Wesson, M. J., Hollenbeck, J. R., Wright, P. M., dan DeShon, R. P. (2001). The assessment of goal commitment: A measurement model meta-analysis. Organizational Behavior and Human Decision Processes, 85(1), 32-55.

La Porta, R., Lopez-de-Silanes, F., Shleifer, A., Vishny, R.W., 1998. Law and finance. Journal of Political Economy 106 (6), 1113-1155.

Locke, E. A., dan Latham, G. P. 1990. A Theory of Goal Setting \& Task Performance. Englewood Cliffs: Prentice-Hall, Inc.

Lord, A. T. 1992. Pressure: A methodological consideration for behavioral research in auditing. Auditing: A Journal of Practice \& Theory, 11(2), 89-108.

Nooteboom, B. (1996). Trust, Opportunism and Governance : A Process and Control Model,
Organizatiom Studies, 17 (6), 985-1010.

Oktina Putri Utami. 2012. Faktor-faktor yang Mempengaruhi Penerimaan

Auditor atas Metode Pilihan Klien. Skripsi Universitas Sultan Ageng Tirtayasa

Sugiyono. 2005. Metode Penelitian Administrasi. Bandung : Alfabeta

Suhendro, Saring. 2006. Motivasi dan Etika Manajemen Laba. Forum Ekonomi Vol. IX No. 2, (9-16)

West, S. G et al. 1995. Structural Equation Model with NonNormal Vaeriaable : Problem and Remedies. In R.H. Hoyt (Ed). Structural Equation Modeling, Concept, Issues and Application. Thousand Oaks. CA : Sage.

Zhang, P., 1999. A bargaining model of audit reporting. Contemporary Accounting Research 16 (1), 167-184.

Undang-Undang Republik Indonesia Nomor 5 Tahun 2011 tentang Akuntan

Publik.http://www.bapepam.go.i d/webakuntan/index.htm www.iapi.or.id, diakses 30Oktober 2012 


\section{Lampiran}

Tabel 2.

Rincian Pengiriman Kuesioner

\begin{tabular}{|l|c|c|}
\multicolumn{1}{c|}{ Keterangan } & Jumlah & Persentase \\
\hline Kuesioner yang didistribusikan & 150 & $100 \%$ \\
Kuesioner yang tidak kembali & 34 & $22,67 \%$ \\
Kuesioner yang tidak diisi lengkap & 2 & $1,33 \%$ \\
Kuesioner yang tidak sesuai kriteria & 5 & $3,33 \%$ \\
Tingkat pengembalian (respon rate) & 116 & $77.33 \%$ \\
Kuesioner yang bisa digunakan & 109 & $72,67 \%$ \\
\hline
\end{tabular}

Kuesioner yang bisa digunakan

Sumber :Data primer diolah (2013)

Tabel 3.

Rincian Pengembalian Kuesioner

\begin{tabular}{|l|l|c|c|c|c|}
\hline No & \multicolumn{1}{|c|}{ Nama Kanto Akuntan Publik } & Kirim & Kembali & $\begin{array}{c}\text { Tidak } \\
\text { Kembali }\end{array}$ & $\begin{array}{c}\text { Dapat } \\
\text { Diolah }\end{array}$ \\
\hline 1 & & Purwantono, Suherman, Surja \& Rekan & & & \\
2 & Kosasih, Nurdiyaman, Tjahjo \& Rekan & 20 & 16 & 4 & 15 \\
3 & Ishak, Saleh, Soewondo \& Rekan & 35 & 30 & 5 & 29 \\
4 & Abubakar Usman \& Rekan & 5 & 3 & 3 & 3 \\
5 & Hendrawinata Eddy \& Siddharta & 30 & 5 & 5 & 5 \\
6 & Tanubrata Sutanto Fahmi \& Rekan & 10 & 6 & 7 & 21 \\
7 & Drs. Rasin, Ichwan \& Rekan & 20 & 7 & 3 & 5 \\
8 & Doli, Bambang, Sudarmadji\& Dadang & 10 & 6 & - & 7 \\
9 & Gani Mulyadi \& Handayani & & 4 & 19 \\
\hline
\end{tabular}

Sumber :Data primer diolah (2013)

Tabel 4.

Gambaran Identitas Responden

\begin{tabular}{|c|c|}
\hline Demografi & Jumlah dan Persentase \\
\hline Jumlah Responden & 109 \\
\hline \multicolumn{2}{|l|}{ KAP } \\
\hline 1. $\operatorname{Big} 4$ & $15(13,76 \%)$ \\
\hline 2. Non Big 4 & $94(86,24 \%)$ \\
\hline \multicolumn{2}{|l|}{ Jenis Kelamin } \\
\hline 1. Pria & $73(66,97 \%)$ \\
\hline 2. Wanita & $36(33,03 \%)$ \\
\hline \multicolumn{2}{|l|}{ Usia } \\
\hline 1. $20-25$ tahun & $63(57,8 \%)$ \\
\hline 2. $25-<30$ tahun & $23(21,1 \%)$ \\
\hline $30-<35$ tahun & $17(15,6 \%)$ \\
\hline $35-40$ tahun & $6(5,5 \%)$ \\
\hline 5. $>40$ tahun & $0(0 \%)$ \\
\hline \multicolumn{2}{|l|}{ Pendidikan } \\
\hline 1. Strata 1 (S1) & $85(78 \%)$ \\
\hline Strata 2 (S2) & $24(22 \%)$ \\
\hline Strata 3 (S3) & $0(0 \%)$ \\
\hline \multicolumn{2}{|l|}{ Jabatan } \\
\hline Junior Auditor & $56(51,38 \%)$ \\
\hline Senior Auditor & $49(44,95 \%)$ \\
\hline Supervisor & $3(2,75 \%)$ \\
\hline 4. Manajer & $1(0,92 \%)$ \\
\hline 5. Partner & $0(0 \%)$ \\
\hline
\end{tabular}

Sumber :Data primer yang diolah, 2013

Normed Chi-Square (CMIN/DF)

Tabel 5.

Computation of degrees of freedom

Number of distinct sample $\quad 136$ 


\begin{tabular}{rr} 
moments: & \\
Number of distinct parameters to be & $\mathbf{3 8}$ \\
estimated: & $\mathbf{9 8}$ \\
\hline Degrees of freedom (136 - 38): & $\mathbf{9 8}$
\end{tabular}

Sumber : Output AMOS 21, 2013

Normed Chi-Square (CMIN/DF)

Tabel 6.

CMIN

\begin{tabular}{|l|rrrrr|}
\hline Model & NPAR & CMIN & DF & P & CMIN/D \\
\hline Default model & 38 & 169.742 & 98 & .000 & $\mathbf{1 . 7 3 2}$ \\
$\begin{array}{l}\text { Saturated model } \\
\text { Independence } \\
\text { model }\end{array}$ & 136 & .000 & 0 & & \\
\hline
\end{tabular}

Sumber : Output AMOS 21, 2013

\section{GoodnessofFit Index (GFI)}

Tabel 7.

RMR, GFI

\begin{tabular}{|l|rrrr|}
\hline Model & RMR & GFI & AGFI & PGFI \\
\hline Default model & .103 & .852 & .795 & .614 \\
Saturated model & .000 & 1.000 & & \\
Independence model & 1.084 & .279 & .183 & .246 \\
\hline
\end{tabular}

Sumber : Output AMOS 21, 2013

\section{Tucker Lewis Index (TLI)}

Tabel 8.

Baseline Comparisons

\begin{tabular}{|l|rrrrr|}
\hline Model & $\begin{array}{r}\text { NFI } \\
\text { Delta1 }\end{array}$ & $\begin{array}{r}\text { RFI } \\
\text { rho } \\
1\end{array}$ & $\begin{array}{r}\text { IFI } \\
\text { Delta } \\
2\end{array}$ & $\begin{array}{r}\text { TLI } \\
\text { rho2 }\end{array}$ & CFI \\
\hline $\begin{array}{l}\text { Default } \\
\text { model }\end{array}$ & .900 & $\begin{array}{r}.87 \\
\begin{array}{l}\text { Saturated } \\
\text { model }\end{array}\end{array}$ & .955 & .944 & .954 \\
$\begin{array}{l}\text { Independen } \\
\text { ce model }\end{array}$ & 1.000 & & 1.000 & & $\begin{array}{r}1.00 \\
0\end{array}$ \\
\hline
\end{tabular}

Sumber : Output AMOS 21, 2013

Root Mean Square Error of Approximation (RMSEA)

Tabel 9.

RMSEA

\begin{tabular}{|l|rrrr|}
\hline Model & RMSEA & LO 90 & HI 90 & PCLOSE \\
\hline Default model & .082 & .061 & .103 & .008 \\
Independence model & .348 & .333 & .363 & .000 \\
\hline
\end{tabular}

Sumber : Output AMOS 21, 2013

Tabel 10.

Regression Weights: (Group number 1 - Default model)

\begin{tabular}{|ll|rcccc|}
\hline & & Estimate & S.E. & C.R. & P & Label \\
\hline CPM <--- & GC & .307 & .109 & 2.806 & .005 & par_15 \\
CPM <--- & LL & -.211 & .093 & -2.274 & .023 & par_16 \\
CPM <--- & T & -.180 & .088 & -2.043 & .041 & par_17 \\
\hline
\end{tabular}

Sumber : Output AMOS 21, 2013 